Maurice A. Deane School of Law at Hofstra University Scholarly Commons at Hofstra Law

Hofstra Law Faculty Scholarship

1988

\title{
Quantitative Risk Assessments As Evidence In Civil Litigation
}

Vern R. Walker

Maurice A. Deane School of Law at Hofstra University

Follow this and additional works at: https://scholarlycommons.law.hofstra.edu/faculty_scholarship

\section{Recommended Citation}

Vern R. Walker, Quantitative Risk Assessments As Evidence In Civil Litigation, 8 Risk Analysis 605 (1988)

Available at: https://scholarlycommons.law.hofstra.edu/faculty_scholarship/511

This Article is brought to you for free and open access by Scholarly Commons at Hofstra Law. It has been accepted for inclusion in Hofstra Law Faculty Scholarship by an authorized administrator of Scholarly Commons at Hofstra Law. For more information, please contact lawcls@hofstra.edu. 


\title{
Quantitative Risk Assessments as Evidence in Civil Litigation
}

\author{
Vern R. Walker ${ }^{1}$
}

Received October 22, 1987; revised February 1, 1988

\begin{abstract}
Those who prepare quantitative risk assessments do not always appreciate that those assessments might be used as evidence in civil litigation. This paper suggests that litigation attorneys, judges, and juries be regarded as audiences to whom the information in the risk assessment must be communicated. The way that a risk assessment is prepared can affect significantly whether litigation is brought at all, the resolution of evidentiary motions involving the risk assessment, as well as the ultimate outcome of the litigation. This paper discusses certain procedural and evidentiary aspects of the civil litigation process in the hope that a better understanding of that process might lead to the preparation of risk assessments that are more adequately understood by juries, judges, and litigants.
\end{abstract}

KEY WORDS: Risk assessment; risk communication; evidence; civil litigation; expert testimony; hearsay.

\section{INTRODUCTION}

Increased attention is being paid to communication of risk to the public generally, not merely to regulatory or managerial decision makers. ${ }^{(1)}$ It is sometimes easy, however, to overlook a particular subset of the general public that our system of governance temporarily turns into decision makers: the jury in a civil trial. Effectively communicating risk to the jury, within the constraints of the law of procedures and evidence, can affect the outcome of civil litigation.

In a lawsuit focused on whether the plaintiff was exposed to a toxic agent and on the risk to the plaintiff due to exposure, a risk assessment can influence the decisions on the ultimate factual issues. Those who prepare risk assessments, or assist in or 'Associate Professor of Law, Hofstra University, Hempstead, New
York 11550. comment on their preparation, should keep litigation attorneys, judges, and juries in mind as important, particular audiences to whom the information in the risk assessment must be communicated. Yet it seems that there is often inadvertence or ignorance on the part of risk assessment authors concerning the role of a quantitative risk assessment as evidence in a civil lawsuit.

This paper discusses many aspects of that role. For the sake of concreteness, the discussion is focused on the use in litigation of a quantitative risk assessment for carcinogenicity, of the sort currently performed by EPA. The discussion also assumes that the applicable rules of evidence and procedure are those governing civil litigation in United States District Courts. These assumptions are made for convenience and concreteness only, and the points discussed apply to a large extent to other agencies, other hazards, and other courts. 
Particular attention is paid to what preparers of a quantitative risk assessment can do to assist the attorneys, judge, and jury in resolving the issues they will face concerning the use of the risk assessment as evidence. Too of ten this litigation perspective is not brought to bear on the preparation of risk assessment documents. If the appropriate use of risk assessments as evidence in civil litigation is to improve, it is important that those who prepare risk assessments do so with the litigation perspective in mind.

\section{USES OF RISK ASSESSMENT IN CIVIL LITIGATION}

In order to evaluate the adequacy of a risk assessment from the standpoint of litigation, it is important to understand the general structure of civil litigation, and the role of a risk assessment in the litigation process. A typical objective of the process is to determine whether the plaintiff should be awarded monetary damages on account of injuries resulting from the defendant's actions. In order for the plaintiff to be awarded damages, he or she must prove all of the essential elements of a legally recognized "cause of action." In a simple tort case, for example, the plaintiff must prove that he has been injured, that the injury was proximately caused by the defendant's activities, that the defendant owed the plaintiff some duty of care, and that the paintiff's injuries resulted because the defendant conducted his activities in a negligent manner. The defendant, on the other hand, seeks to convince the trier of fact (the jury, or in some instances the judge) that the plaintiff has not met the burden of proof placed upon him by law to establish all of the required factual elements of his case, or that one or more relevant defenses exist. Attorneys for the plaintiff or the defendant may try to use a risk assessment as evidence to help prove or disprove various assertions relevant to the case.

\subsection{Qualitative Evidence}

In some lawsuits, one assertion at issue is whether it is possible for a specific agent to cause cancer in humans at all. This assertion is qualitative in nature, rather than quantitative, and represents the outcome of what the National Academy of Sciences has called "hazard identification." ${ }^{(2,3)}$ Whether an agent can cause cancer in humans may have legal significance even if a quantitative risk assessment is not available. Such a qualitative assertion, for example, may be part of a plaintiff's argument that a product containing a certain chemical was defective in its design or labeling. A plaintiff might be arguing that the ability of an ingredient chemical to cause cancer in humans itself renders the product design defective, and outweighs any benefits the product might have in its normal use.

A plaintiff might also claim that exposure to an agent has caused an emotional injury to the plaintiff. Such injury, it might be claimed, is in the form of "cancerphobia" (a psychological condition diagnosable by psychologists or psychiatrists) or fear of cancer (a form of emotional distress, the diagnosis of which might not require an expert). The plaintiff might be arguing that such injuries were reasonably foreseeable by the manufacturer.

As qualitative evidence, the exposure assessment portion of a risk assessment might also be relevant. ${ }^{(2,3)}$ A plaintiff might be seeking damages for injury to property-arguing, for example, that his property was rendered unfit for its normal use due to contamination by the defendant's product or waste. The plaintiff might try to rely on the exposure discussion of a risk assessment to help establish how humans can become exposed to an agent in potentially harmful doses.

A plaintiff might also be seeking punitive damages, arguing that the defendant acted with knowing and reckless disregard of public health. The defendant could not have acted with knowledge, however, unless it is true that certain exposures can in fact result in cancer.

The defendant, on the other hand, might find an EPA risk assessment useful in helping to establish that certain toxicological or epidemiological studies are methodologically flawed and unreliable, that risk of cancer is unproven and speculative, or that certain situations make exposure extremely unlikely.

\subsection{Quantitative Evidence}

If data are available measuring the plaintiff's exposure, and if dose-response research is available for the chemical, then the plaintiff might try to quantify the likelihood that cancer will result from the plaintiff's own personal exposure. Some jurisdictions require that, before a plaintiff who does not 
have cancer is allowed to recover damages for increased risk of cancer, the plaintiff must establish that it is probable that he will develop cancer as a result of his exposure. ${ }^{(4)}$ This requirement has sometimes been interpreted quantitatively, as requiring that the plaintiff prove that he has incurred a greater than $50 \%$ risk of injury due to the defendant's actions. ${ }^{(5)}$ The relevance of a quantitative risk assessment to this issue is clear.

A quantitative risk assessment also might be used by a plaintiff to help establish a case for medical surveillance. ${ }^{(4,6)}$ Such an issue might arise if the plaintiff claims that he has incurred an increased risk that, although not great enough to warrant immediate payment of damages, is sufficiently high that unusual medical surveillance is indicated.

In either of these situations, the plaintiff is interested in establishing not only the possibility that exposure to an agent can cause cancer, but also the amount of excess risk that he has incurred due to his exposure. The defendant, in contrast, has an interest in establishing that the plaintiff's risk, if any, is either normal or acceptably low. Introducing the quantitative risk assessment into evidence may help either side to establish his or her case on these issues.

\section{MEANS OF COMMUNICATING A RISK ASSESSMENT TO THE JURY}

When the evidence to be put to a jury includes the contents of a quantitative risk assessment, with its typical scientific content and technical style, the proponent of the evidence (whether plaintiff or defendant) has three principal avenues of approach: present the expert testimony of the author of the risk assessment, read from the document itself or submit it to the jury, or put another expert on the witness stand who will rely on the risk assessment in reaching his or her expert opinions in the case. Each of these approaches has its advantages and disadvantages. Each also gives rise to special legal questions that the judge may have to resolve on motions before the trial begins, or on objections during the trial.

\subsection{The Author as Witness}

From the standpoint of the proponent of the evidence, the strongest presentation of the informa- tion in the risk assessment might be the testimony of one of the authors. The author would be familiar with the toxicological and other scientific data upon which the risk assessment was performed, and it is sometimes difficult to find an expert who is familiar with the particular body of data and literature-or who is willing to become so within a reasonable time and for a reasonable fee. An author also should be able to testify knowledgeably on the assumptions and techniques employed in performing the risk assessment itself. The author, therefore, may be able to explain to the jury the reasoning behind the risk assessment, to answer follow-up questions, and to defend the risk assessment on cross-examination. In theory, therefore, calling the author as a witness may be the preferred means of putting the risk assessment before the jury.

Theory, of course, is not practice. While it is better as a rule to present a good witness than just read to the jury from a document, especially when the contents of the document require added explanation, the best course ultimately depends largely on the personality of the potential witness and on his ability to communicate to the jury.

If the author is an employee of a regulatory agency, additional advantages and disadvantages arise from the standpoint of the proponent of the evidence. The obvious advantage is the authoritative credential of the author's employment, and the independence of judgment that is presumed to attend that office. A practical disadvantage is that the proponent probably would have no opportunity to "prepare" the witness, to determine whether the witness's testimony would be "favorable," or to test the witness's answers under mock cross-examination. These constraints can add considerable uncertainty and risk to relying on such an author as a witness.

These considerations can have particular force in the case of a quantitative risk assessment. There might be many uncertainties about how an author would apply the regulatory risk assessment methodology to a concrete situation, if the objective is to derive the best estimate (not conservative estimate) of actual (not just possible) risk. Some of these issues are relatively uncharted territory from a regulatory standpoint. They are also issues upon which the relevant regulatory officials perhaps have not expressed their views publicly. Discovering the author's views for the first time in a deposition, let alone at trial, might undermine entirely the hoped-for effect. Thus, the attorney who wishes to call as a witness an 
author of a quantitative risk assessment has many factors to weigh in deciding to do so.

\subsection{The Document Itself as Evidence}

The proponent might seek to have the risk assessment itself submitted to the jury, and might ask the court to allow the reading of portions of it aloud during the trial. If the author is not available or is not desirable as a witness, this approach sometimes might be the better alternative. Documents are cheaper and more available than expert witnesses, and sometimes can be just as authoritative.

In general, however, submitting the document itself or reading it aloud is probably not as effective a presentation as having a witness explain and advocate the position taken in the document. Quantitative risk assessments, moreover, are often impenetrable documents from the standpoint of the typical jury. The usefulness of such a document depends in large part on the number and quality of the "quotable" or "usable" portions: the quotable portions can be effective, and the remainder probably will be disregarded.

\subsection{An Expert Witness Relying on the Risk Assessment}

The third principal means of communicating the risk assessment to the jury is for a party to retain an expert witness to review the risk assessment and to rely upon it in formulating his or her expert opinions. Then the expert witness can describe in his testimony, in the process of recounting the bases for his expert opinions, both the risk assessment procedure and its conclusions.

This approach has certain advantages over either of the first two approaches. Unlike the situation with the regulatory author, the expert testimony can be prepared in advance so as to take into account the peculiar facts of the particular case at issue. Unlike the approach of merely reading the document to the jury, the expert witness will be able to explain the technical issues and answer questions.

The expert testimony can also be coordinated with that of other witnesses. For example, the testimony of a toxicological expert can be coordinated with that of a sampling expert, an expert on pharmacokinetics, or an epidemiologist. Such coordination allows the party to present a more complete and understandable explanation of the issues to the jury.

There are, on the other hand, relative disadvantages to retaining an expert witness. The independence and authoritativeness of the author or of the document itself may be lost. It will also be far more expensive to retain an expert witness than merely to read or to present the risk assessment to the jury. It may be difficult, moreover, to find an expert who can testify to the complete methodology employed in the risk assessment, especially if the methodological presentation in the document is not complete. It may be possible, of course, to combine all three approaches in a particular case, so as to obtain the combined advantages from each approach.

\section{GENERAL PROBLEMS IN COMMUNICATING TO THE JURY}

Whatever means of communication are selected, an attorney faces a number of general problems in communicating the contents of the risk assessment to the jury. Techniques of presenting technical and scientific evidence vary widely from one trial attorney to the next, and it is not appropriate here to discuss style of courtroom presentation. What is worthwhile, however, is to discuss briefly several communication problems that become particularly difficult in the case of risk assessments.

The objective of a trial attorney is, of course, roughly the same whether the evidence at hand is a risk assessment or any other technical information. Through the direct testimony of expert witnesses, the jury must be educated on the technical issues at the appropriate level of detail. In order to accomplish this, the direct testimony on the risk assessment must be integrated with other expert testimony, so that a clear, overall account is presented to the jury. On cross-examination of an expert witness, on the other hand, those issues are usually explored that the witness has ignored or deemphasized because they are unfavorable. The quality of a risk assessment can affect the likelihood of success at achieving these
objectives.

\subsection{Mode of Presentation in the Risk Assessment}

The most obvious difficulty for a trial attorney is to communicate the technical contents of the risk assessment. It is extremely difficult to convey to the 
jury a proper understanding of not only the toxicological, epidemiological, environmental, and exposure data utilized in many risk assessments, but also the statistical and inferential techniques used to process those data and arrive at findings, mixed conclusions of science and policy, and regulatory positions. Those findings and conclusions themselves are sometimes not properly understood unless the data and the technical methodology employed in reaching them are in turn understood. Even the ordinary words used to express conclusions (such as the word "probable" in "probable human carcinogen") can be misinterpreted unless the methodology leading to their use is properly understood.

Recognizing this difficulty of communication, however, authors of risk assessments sometimes take one or more of three approaches-each of which can render a disservice to litigation. The first approach is to try to put a selective summary of the risk assessment into nontechnical terms. The selection process and the constraints of nontechnical language, however, can create significant bias in interpretations of the risk assessment. If a readable summary is provided, only that summary might be read by the attorneys or the judge, or at least only that summary might be heard by the jury. A readable and understandable risk assessment is necessary, but the readable and understandable portion should not be merely a highly selected summary. The challenge is to make every important assumption, limitation, inference, and conclusion understandable - not merely to end a technical tour de force with a restatement of understandable (but regrettably unqualified) conclusions.

A highly selective summary, without adequate qualifiers in language that a nonexpert can understand, also increases the likelihood that borderline or unsound cases will be filed in court. An attorney approached to handle a contingency tort case often consults relevant regulatory documents to make a preliminary assessment of the merits of the claim. The prospective client, in turn, relies upon the attorney to evaluate the strength of the case from a litigation perspective. Unfortunately, it is too much to expect an average attorney to read and understand more in a quantitative risk assessment than the selective summary. Inadequate summaries therefore can lead to more cases being filed, more money and court time wasted, than would otherwise be the case.

The second approach to the difficulty is to write the risk assessment for nonexperts only, in the sense that technical formulations are omitted altogether. This approach is far worse than the first. At least with a technical discussion and a readable summary, an expert witness can understand what the risk assessment methodology was, critique it, and explain it to the jury. If the technical details are absent altogether, the expert witness is forced to speculate and to run the risk of being discredited for his ignorance or his speculation. It is extremely unfortunate, from the standpoint of litigation, when a risk assessment does not contain all of the technical information necessary for reconstructing and evaluating every step of the risk assessment process.

The third approach to the difficulty is to provide only a technical account, and to resist straying into language that can be misunderstood by a nonexpert. This approach provides all the technical information needed to reconstruct the risk assessment process, but leaves to other experts the task of explaining the meaning and significance to the jury. Even if this approach were considered an acceptable approach for government officials to take toward informing the public, it would fail to inform the nonexpert decision makers and risk managers within the agencies, who need to know what the risk assessment is saying in order to make enlightened decisions. A technical risk assessment must be interpreted in order to be useful to anyone except risk assessment experts themselves.

Thus, a critical challenge for authors of risk assessments is to explain to nonscientists all of the critical elements of the risk assessment: its data, assumptions, methodology, policy decisions, findings, and conclusions. Anything less than this should be regarded as a failure to communicate fully.

All of this information and interpretation, moreover, should be contained in the risk assessment document itself, or at least explicitly incorporated by reference. Each risk assessment document should contain, in readily understandable language, all of the information needed to reconstruct, interpret, and explain that risk assessment. The reason for this is that it is often difficult or impossible for an attorney to demonstrate to a judge, let alone to a jury, that a qualifying or explanatory statement in one regulatory document applies to a specific conclusion in another document. For example, it may be difficult to prove that an EPA statement about "linearized multistage procedure" in one document in 1985 is also true of the "linear multistage model" used for an EPA risk assessment issued in 1987. The relevance of the prior 
statement for the later risk assessment may be extremely difficult to establish unless the cross-reference is clearly indicated in the later risk assessment. In addition, multiple cross-references can make oral testimony a bewilderment. By far the most effective approach, from the standpoint of litigation, is to include all of the relevant discussion in the risk assessment document itself.

\subsection{Contents of the Risk Assessment Document}

Just as some general comments can be made about the mode of presentation in the risk assessment, it is also possible to make several general points about the contents themselves. What is needed is for the authors of a risk assessment to help the attorneys, judge, and jury identify and understand the elements of the risk assessment that are of importance to them. It is efficient for experts writing for each other to use "shorthand" terminology, and to assume that the reader "knows what I mean" and will "read into" the assertions of the risk assessment the proper qualifiers. But nonexpert readers need, and deserve, certain assistance that the authors can provide. Some suggestions follow.

First, there should be a clear and concise articulation of the information that is lacking to the authors. As the National Academy of Sciences has pointed out, risk assessment is needed precisely in areas where there is a lack of information. ${ }^{(2)}$ The nonexpert needs to know where data and knowledge stop, where assumptions are made, and where inference begins. In presenting a case to a jury, it is often very important to be able to identify exactly what we know independently of any risk assessment methodology, before explaining how that methodology proceeds beyond what we know.

Second, it is important to identify in the risk assessment what the assumptions are. Many factual assumptions may have been made to fill gaps in the factual knowledge of the risk assessment's author-e.g., assumptions about exposure or dosage. It is extremely important in litigation, where the proper decision often rests upon a distinction between what is known and what is assumed or speculated, to be able to determine what the assumptions are in a given risk assessment.

Third, it is important to articulate in the risk assessment what is science and what is policy. Science includes more than knowledge of data: it in- cludes inference and prediction employing basic principles, well-established theories, and even hypotheses. But a given science stays within some boundaries recognized by experts in the field. Such sciences as pathology, psychology, toxicology, epidemiology, environmental chemistry, and medicine, for example, are well-established disciplines, and the judge and jury will be interested in determining which assertions in the risk assessment pertain to such recognized fields.

On the other hand, regulatory policy is not necessarily purely scientific judgment. A decision to "count" both malignant and benign tumors in calculating a risk value might not be a decision that a pathologist, qua pathologist, normally makes, although a pathologist can certainly have opinions about whether specific tumors are malignant or benign. Likewise, a decision to adopt for regulatory purposes a linearized multistage model in order to extrapolate low-dose risks is not necessarily a scientific conclusion. In a particular circumstance, there may not be a completely scientific or experimental basis for such a decision, and it has to be regarded as principally a decision of regulatory policy. The preparer of a risk assessment should not assume that even scientific experts can always identify regulatory policy decisions.

Next, the risk assessment should articulate, to the extent possible, the sensitivity of the various conclusions to the assumptions and the regulatory policy decisions that have been employed. Inferences proceed from facts, assumptions, and inferential rules or principles-whether the latter are derived from scientific theory (e.g., the principle of mass balance) or regulatory policy (e.g., "count benign tumors"). All conclusions have associated with them a degree of confidence, a level of uncertainty. Some uncertainty derives from lack of confidence in the data, some from the assumptions, some from the inference rules employed. How such uncertainties interact is usually not obvious: some uncertainties offset others, some are additive to others, some outweigh and virtually engulf others. The authors of the risk assessment, the experts who have analyzed the issues, need to communicate to the nonexpert the extent to which the confidence in the conclusions would be affected by error in the premises. This is the best-and perhaps only - way in which the importance and role of the assumptions and policy decisions can be communicated. In addition, the level of confidence or uncertainty attending a conclusion can be a significant 
issue in litigation, where likelihood and burden of proof often play deciding roles.

Finally, the risk assessment should identify the degree of uncertainty associated not only with the overall conclusion, but with each major conclusion of the risk assessment. Major conclusions of importance in litigation generally occur at each stage of the risk assessment: hazard identification, dose-response assessment, exposure assessment, and risk characterization. It is often insufficient merely to include a confidence characterization for the "bottom line" conclusion, because litigation often revolves around subsidiary issues dealt with in the risk assessment on the way to the final conclusion.

\section{SPECIAL ISSUES ARISING IN TRYING TO COMMUNICATE THE RISK ASSESSMENT TO THE JURY}

In addition to the general problems of communication just discussed, attorneys can also face special problems in trying to get the opportunity to communicate the risk assessment to the jury. Some of these problems arise in the context of evidentiary objections that will be decided by the judge prior to letting the risk assessment into evidence. The outcome of such motions or objections can be affected by how the risk assessment itself is prepared.

\subsection{Testimony by Governmental Employees May Be Barred}

If a party seeks to have a governmental employee (e.g., the author of a risk assessment) deposed or subpoenaed for testimony at trial, he may find that the employee will not comply or cooperate with the subpoena. For example, pursuant to current EPA regulations, ${ }^{(7)}$ no EPA employee may provide testimony or produce documents in a private civil court proceeding because of the employee's official relationship with EPA, or concerning information acquired in the course of performing official duties, unless authorized to do so by EPA's General Counsel. $^{2}$

\footnotetext{
${ }^{2}$ Another example of an agency forbidding its agents to testify in court proceedings is apparently the federal Center for Disease
}

The stated purpose of the regulation is to ensure that employees' official time is used only for official purposes, to ensure that public funds are not used for private purposes, and to maintain the impartiality of EPA with respect to private litigants.

If EPA's General Counsel declines to approve compliance with a subpoena, the employee must appear at the required time and place, produce a copy of the regulations prohibiting testimony, and respectfully refuse to provide any testimony or produce any documents. The basis for the General Counsel's approval to testify would be that compliance with the request "would clearly be in the interests of EPA."(7)

A final risk assessment document would be available through EPA's public information channels, including Freedom of Information Act requests. Drafts of a document that is not yet final, however, might not be made available. Other internal agency memoranda concerning the risk assessment also might not be made available, although they could be important from the standpoint of litigation. Background documents can be important sources of information concerning the database used for the risk assessment, the significance of the assumptions made, the meaning of the conclusions reached, and the internal review procedures leading to the final document.

It is not appropriate here to evaluate the policy behind these EPA regulations, or whether governmental agencies that prepare and issue quantitative risk assessments should provide personnel to explain such documents and the relevant issues in civil litigation. The existence of such regulations, however, indicates that risk assessment documents should be prepared with civil litigation more in mind, taking into account the needs and unanswered questions of litigants, judges, and juries. The need for testimony from regulatory authors is, to some extent, inversely proportional to the adequacy of the risk assessment document itself for litigation purposes: the clearer and more complete the document, the less private litigants might press for explanatory testimony.

Control. Kehm v. Procter \& Gamble Mfg. Co., 724 Federal Reporter, 2d Series at 618 note 2 (8th Cir. 1983). For regulations prohibiting unauthorized testimony by employees of the Food and Drug Administration, see the Code of Federal Regulations, Title 21, Part 20, Subpart A. For regulations of the U.S. Department of Labor procedurally similar to those of EPA, see the Code of Federal Regulations, Title 29, Part 2, Subpart C. 


\subsection{Hearsay Objections to the Risk Assessment Document}

An attempt to introduce the risk assessment document itself as evidence may encounter an objection that it should be barred as " hearsay." Hearsay is a statement (here, in written form) offered in evidence to prove the truth of the matter asserted, but without opportunity to cross-examine at trial the declarant who made the assertion. The opportunity for cross-examination of the author would appear to be particularly important when dealing with risk assessments, in view of the complexity of methodology, the obscurity of meaning, and the degree of professional judgment found in many risk assessments.

Rule 802 of the Federal Rules of Evidence provides the general proscription against allowing hearsay into evidence. Motions on hearsay are debates over whether the risk assessment itself should be admissible as evidence. Motions arguing that the risk assessment should not be admitted would emphasize that the technical nature of the content necessitates cross-examination if the document is to be properly understood. In addition, such a motion might argue that the quantitative risk assessment contains disguised regulatory policy decisions that take more factors into account than merely scientific validity. The argument would conclude that opportunity for cross-examination is the only safeguard against misuse of the risk assessment.

Depending upon the source of the risk assessment, the hearsay exception allowing admission of public records and reports (Federal Rule of Evidence $803(8)$ ) will probably play a central role in the debate. Rule $803(8)(C)$ allows an exception to the general rule against the admissibility of hearsay in civil actions in the case of "records, reports, statements, or data compilations" of public agencies which set forth "factual findings resulting from an investigation made pursuant to authority granted by law, unless the sources of information or other circumstances indicate lack of trustworthiness." (8) The Rule makes no distinction between federal and nonfederal agencies as sources of the report. ${ }^{3}$ The general presumption against the reliability of hearsay is overcome by the policy that findings are presumed to be reliable if duly made in the course of a governmental investigation that has been undertaken pursuant to a legal duty and for an important governmental purpose. ${ }^{(9)}$
Although the Rule uses the phrase "factual findings," the courts have tended to give the words a broad meaning, and have of ten admitted government reports setting forth agency opinions and conclusions. ${ }^{(10)}$ Even background information describing past events or material culled from other documents in the agency record might be included in the hearsay exception. ${ }^{(11)}$ Scientific reports are not treated differently from other types of reports, and the fact that a study contains "tentative conclusions as well as statistical findings" might not defeat the applicability of the Rule. ${ }^{(12)}$ Staff memoranda, however, proposed draft reports, and "interim" reports that are never adopted by the agency itself might not constitute "factual findings" under the Rule. ${ }^{(11,13)}$ Documents or portions of documents, moreover, for which it would be "difficult, if not impossible" to separate those elements that would qualify as "factual findings" from those that are primarily conjectures by the agency "as to how the future will or should unfold" may be held to be not covered by the Rule's hearsay exception. ${ }^{(11)}$

A risk assessment issued by an agency may also be ruled inadmissable as untrustworthy on a caseby-case basis if sufficient negative factors are present. Such factors may include timeliness of the study or report, whether a hearing was held or a noticeand-comment procedure was utilized, the skill or experience of the official who conducted the study, possible motivation problems, and other such factors affecting reliability. ${ }^{(14)}$ The presumption, however, will be that the risk assessment document is admissible if it contains the "factual findings" of a government report or study, and the burden will be on the opponent to establish the unreliability of the particular document.

A major problem with hearsay motions dealing with risk assessments is that the evidentiary issues peculiar to risk assessments are not usually obvious to the attorneys, let alone the judge, and are often difficult to articulate clearly even if recognized. The general recommendations discussed above would greatly assist the attorneys and the court in arriving at a fair ruling on hearsay. Also helpful would be a risk assessment document that contains a description

\footnotetext{
${ }^{3}$ Results of studies by state agencies may be covered by the Rule Kehm v. Procter \& Gamble Mfg. Co., 724 Federal Reporter, 2d Series at 617-620 (8th Cir. 1983), as well as the documents of foreign offices or agencies, In re Japanese Electronic Products Antitrust Litigation, 723 Federal Reporter, 2d Series at 271-274 (3d Cir. 1983)
} 
of the administrative procedure followed in producing the risk assessment-a description that would help the court determine whether reliance should be placed on the document in the absence of the author.

\subsection{Objections to Reliance by an Expert Witness}

The third means of putting the risk assessment information into evidence, besides testimony by the author and using the document itself, is to have an expert witness review the risk assessment, along with other relevant material and the facts of the particular case, and rely on the risk assessment in reaching his or her own expert opinion. The contents of the risk assessment relied upon can then be discussed by the expert on the witness stand. ${ }^{(9)}$ This approach can avoid hearsay objections because, under Federal Rule of Evidence 703, facts or data used by an expert witness to base an opinion or inference need not be admissible in evidence if they are "of a type reasonably relied upon by experts in the particular field."(15)

A motion to bar an expert's reliance on a particular risk assessment probably would argue that the risk assessment is not the type of information reasonably relied upon by experts in the relevant field. The strength of this argument would depend upon the nature and contents of the particular risk assessment itself. For example, a one-page risk assessment that was produced by a single author who did not have special expertise in the scientific area, or who did not review the primary studies or database, or whose report was not peer-reviewed, might not be the type of information normally relied upon by a diagnosing physician. The opposing motion might also be based upon the breadth of expertise of the expert witness, and upon whether that expertise extends to the area of quantitative risk assessment. For example, if the expert wishes to rely on the calculated estimate of risk, but does not have the expertise to explain how the quantitative estimate was arrived at, how it should be interpreted, or what limitations there should be on its use, the court might decide that the risk assessment is not the type of information reasonably relied upon by such experts as the witness.

Rule 703, however, is intended to give reasonably wide latitude to the expert to choose the basis of his or her opinions. The issue is not whether the court thinks that the risk assessment is reliable, but whether experts in the relevant discipline deem such risk assessments to be reasonably reliable. ${ }^{(9)}$ The court is more likely to deny a motion seeking to bar the witness from relying on a risk assessment if the judge believes that the document provides the opposing party with sufficient information to permit meaningful cross-examination on the justification for the expert's reliance. At trial, difficulties with the risk assessment's reliability become problems for the expert's credibility, instead of problems of admissibility.

\subsection{Objections Based on Unfair Prejudice}

An additional objection that might be raised against any of the above means of communicating the risk assessment to the jury is based on the claim that such communication would be prejudicial to the opposing party. Federal Rule of Evidence 403 provides that even relevant or otherwise admissible evidence may be excluded by the judge if its probative value is substantially outweighed by the danger of unfair prejudice, confusion of the issues, or of being misleading to the jury. By "unfair prejudice" is meant an undue tendency to suggest a decision on an improper basis-commonly, but not necessarily, an emotional one. ${ }^{(16)}$ For example, in the absence of sufficient facts in evidence in a particular case, the reading of a published scientific article might be barred as inviting unwarranted speculation by the jury about the facts ${ }^{(12)}$; testimony might be barred if it would convey a false aura of scientific infallibility ${ }^{(5)}$; or a document might be excluded (as well as testimony about its contents) if its aura of official trustworthiness would not be commensurate with its actual reliability. ${ }^{(13)}$

The decision on a Rule $\mathbf{4 0 3}$ motion to exclude a risk assessment may depend on the ability of the motion's proponent to explain clearly and in detail exactly how the evidence would be prejudicial, confusing, and misleading. Such an argument might include, for example, an explanation of how the risk assessment misleadingly mixes science, speculation, and regulatory policy in a way that cannot be sorted out for a jury. And to the extent that the risk assessment's substantive contribution to the case is a minor one or appears somewhat obscure, there is a greater likelihood of its being excluded from evidence. ${ }^{(5)}$ A clear assessment, on the other hand, would help the court to identify exactly what role the risk assessment can play in establishing which assertions on which issues (e.g., cancerphobia, intentional inflic- 
tion of emotional distress, contamination of property, etc.). As the probative value increases and the danger of confusion decreases, there is greater chance of the risk assessment's being admitted into evidence.

\section{CONCLUSION}

Those who prepare risk assessments, or assist in or comment on their preparation, should keep in mind the interests and needs of litigation attorneys, judges, and juries. Communication with these special audiences should be of concern to regulators and risk assessment authors, for the way a risk assessment is prepared can affect significantly whether litigation is brought at all, the resolution of evidentiary motions involving the risk assessment, as well as the ultimate outcome of the litigation. A better understanding of the litigation process, and increased attention to the possible role of risk assessments in that process, may lead to the preparation of risk assessments that assist, or at least do not hinder, the litigation process.

\section{REFERENCES}

1. R. L. Keeney and D. v. Winterfeldt, "Improving Risk Communication," Risk Analysis 6, 417-424 (1986).

2. National Research Council, Risk Assessment in the Federal Government: Managing the Process (1983).
3. United States Environmental Protection Agency, "Guidelines for Carcinogen Risk Assessment," 51 Federal Register 3399234003 (September 24, 1986).

4. Herber v. Johns-Manville Corp., 785 Federal Reporter, 2d Series 79-90 (3d Cir. 1986).

5. In re "Agent Orange" Product Liability Litigation, 611 Federal Supplement 1223-1266 (E.D.N.Y. 1985).

6. Ayers $v$. Township of Jackson, 106 New Jersey Reports 557, 525 Atlantic Reporter, 2d Series 287 (1987).

7. United States Environmental Protection Agency, "Public Information; Testimony by Employees and Production of Documents in Civil Legal Proceedings: Final Rule," 50 Federal Register 32386-32388 (August 9, 1985), codified at Code of Federal Regulations, Title 40, Part 2, Subpart C.

8. Federal Rule of Evidence 803(8)(C), United States Code Annotated (1987).

9. In re Japanese Electronic Products Antitrust Litigation, 723 Federal Reporter, 2d Series 238-319 (3d Cir. 1983), reversed on other grounds, 106 Supreme Court Reporter 1348-1367 (1986)

10. Kehm v. Proctor \& Gamble Mfg. Co., 724 Federal Reporter, $2 d$ Series 613-630 (8th Cir. 1983).

11. United States v. American Telephone and Telegraph Co., 498 Federal Supplement 353-368 (D.C.D.C. 1980).

12. Ellis u. International Playtex, Inc., 745 Federal Reporter, $2 d$ Series 292-307 (4th Cir. 1984).

13. City of New York v. Pullman Inc., 662 Federal Reporter, $2 d$ Series 910-921 (2d Cir. 1981), certiorari denied, 454 United States Reports 1164 (1982).

14. Notes of the Senate Committee on the Judiciary, Senate Report No. 93-1277.

15. Federal Rule of Evidence 703, United States Code Annotated (1987).

16. Notes of the Advisory Committee on the Proposed Rules, Note on Rule 403, published in United States Code Annotated (1987). 